\title{
Formal Learning Sequences and Progression in the Studio: A Framework for Digital Design Education
}

\author{
Pontus Wärnestål \\ School of Information Technology \\ Halmstad University, Sweden
}

pontus.warnestal@hh.se

\begin{abstract}
This paper examines how to leverage the design studio learning environment throughout longterm Digital Design education in order to support students to progress from tactical, well-defined, device-centric routine design, to confidently design sustainable solutions for strategic, complex, problems for a wide range of devices and platforms in the digital space. We present a framework derived from literature on design, creativity, and theories on learning that: (a) implements a theory of formal learning sequences as a user-centered design process in the studio; and (b) describes design challenge progressions in the design studio environment modeled in seven dimensions. The framework can be used as a tool for designing, evaluating, and communicating course progressions within - and between series of - design studio courses. This approach is evaluated by implementing a formal learning sequence framework in a series of design studio courses that progress in an undergraduate design-oriented Informatics program. Reflections from students, teachers, and external clients indicate high student motivation and learning goal achievement, high teacher satisfaction and skill development, and high satisfaction among external clients.
\end{abstract}

Keywords: Education, design studio learning, Human-Computer Interaction, user-centered design, formation and transformation of knowledge

\section{Introduction}

Over the last few decades, digital technologies have driven deep and profound changes in our relationships to communication, culture, and society at large. This has caused Informatics, Human-Computer Interaction (HCI), Computer Science, and Digital Design to undergo a silent revolution the past two decades: human-centric innovation, user experience, and strategic deviceagnostic service design do not only complement the traditional product-centric perspective, it has

Material published as part of this publication, either on-line or in print, is copyrighted by the Informing Science Institute.

Permission to make digital or paper copy of part or all of these works for personal or classroom use is granted without fee provided that the copies are not made or distributed for profit or commercial advantage AND that copies 1) bear this notice in full and 2) give the full citation on the first page. It is permissible to abstract these works so long as credit is given. To copy in all other cases or to republish or to post on a server or to redistribute to lists requires specific permission and payment of a fee. Contact Publisher@InformingScience.org to request redistribution permission. even been claimed to dominate it (Kolko, 2010b; Norman, 2007).

Design and information science are both traditionally viewed as problem-solving disciplines. Extending traditional problem-solving to encompass "wicked" problem identification (Rittel \& Webber, 1973), information technologies are increasingly being viewed as creative practices (Blumenthal, Inouye, \& 
Mitchell, 2003). Furthermore, procedural aspects of design such as sketching and visualization skills have increasingly gained attention as being key assets for interaction designers (Buxton, 2010; Stolterman, 2008). This cross-disciplinary ability to combine problem solving with creativity is needed for today's strategic perspective on digital service design. This becomes even more important as ubiquitous mobile connectedness increasingly bridges analogue and digital touch-points with wider ranges of users.

Digital design in the 2010s thus rapidly and continuously puts new requirements on theory and practice. Educational initiatives aiming to teach digital design need to evolve with the field and resonate with not only declarative academic requirements, but also the procedural craftsmanship and reflective qualities of design practice (Kolko, 2011; Schön, 1983; Selander, 2008; Wärnestål $\&$ Lindqvist, 2013). As theory and design practice are being revitalized in this context, there is room for improvement in how we prepare students to deal with these sorts of problems professionally. To this end, several suggestions have been voiced, such as arts-based learning (Snyder, Heckman, \& Scialdone, 2009), studio-based and apprenticeship courses (e.g. Sas, 2006; Wang, 2010), and learning in authentic, off-campus contexts (Wärnestål \& Lindqvist, 2012). Despite some criticisms being voiced regarding studio pedagogy, some scholars have recommended that the studio should be the default learning environment for design-oriented education (cf. Cho \& Cho, 2014; Wang, 2010). However, there is a lack of formal methods that support: (a) implementation of designerly (Cross, 2001; Schön, 1983; Stolterman, 2008) ways of working in studiooriented learning environments for Digital Design; and (b) implementation of controlled progression based on individual needs throughout several years of education.

In the work presented here, we cast a wide net on the notion of studio pedagogy as it is designed into design-oriented education. We take the standpoint that if continuous reflection is indeed important to foster designerly ways of working, a studio course does not stand on its own. The course is always part of something bigger, and needs to be designed with contextual reflection and progression in mind. This paper examines how to leverage the design studio concept throughout several years of studies in order to support the students to not only master tactical, well-defined, device-centric routine design, but also confidently design sustainable solutions for strategic, wicked, and device-agnostic problems. This ability is increasingly being required by professional digital designers the coming decade and beyond (Kolko, 2010a). The contribution is a theoretical framework for formal learning sequences and progressions that can be used by studio course instructors as a tool for systematically increase the design challenges in and between studio courses, as well as a model for implementing transformational learning sequences (Selander, 2008).

\section{Literature Review}

This section outlines important aspects of digital design, studio-based pedagogy, and transformational learning that form the building blocks of the formal learning framework presented in this paper.

\section{Aspects of Digital Design and Creativity}

All design-oriented professionals require abilities beyond technical competence: to interpret complex and ambiguous situations, i.e. "wicked problems" (Rittel \& Webber, 1973); to interact with experts from other specialties and disciplines (Antunes, Xiao, \& Pino, 2014); and to constructively evaluate their own work and the work of others (Löwgren \& Stolterman, 2004). When considering digital design (interaction design, user experience design, and related HCI fields), yet more abilities and skillsets emerge. A digital designer must not only be able to layout controls on a screen, or map users' mental models to an information architecture; s/he must also study, design for, and evaluate long-term interactions between different systems, devices, and platforms. To- 
day's designers must therefore be able to engage in sustainability, privacy, innovation, brand, business modeling, service design, and emotional user experiences (Kolko, 2010b), to name a few aspects that HCI programs based in traditional Computer Science typically do not emphasize. This long-term view of effects ties into business viability as well as sustainability aspects of IT use, and complements the traditional, more tactical, notion of HCI design. A tactical design focuses on a specific product or service, and tends to measure objective product attributes, such as usability. A strategic design takes into account long-term use, sustainability and viability, and measures effects on user experience in relation to identity, brand, and business model, and so forth. (Levy, 2015). It also encompasses multiple touch points and target platforms as IT is weaved into everyday day life (Yoo, 2010).

Given the spread of devices, and constantly emerging target platforms for design efforts, a designer needs to be able to sketch and prototype solutions for both known (given) and previously unknown devices and interaction contexts. Furthermore, there is often a lack of robust design tools for the newer interaction modalities and devices. This puts requirements on designers to be able to sketch interactions using: (a) very plain and basic tools such as pen and paper; and (b) home-made design tools (Buxton, 2010). Examples of this would include setting up Wizard-ofOz environments for speech interaction (Dahlbäck, Jönsson, \& Ahrenberg, 1993), or using available technology to prototype for augmented reality solutions and wearables, and so forth.

Innovative digital design is not only about creating new services; it must also be successful in a market. Therefore, designers need to be able to systematically finding niches and needs given a market situation. This research step is part theory-driven, part about audits and user research. $R e$ search is thus an integral part of the design process (Cooper, Reimann, \& Cronin, 2012; Goodwin, 2011). The knowledge generated by this research is then used as a foundation for the generative design where innovative potential is harnessed to product or service solutions. The generative perspective is anchored to sketching and prototyping, where procedural knowledge is used to inform the designer about the design problem (Buxton, 2010). The creative leap between research and generative design is referred to as design synthesis (Kolko, 2010a). The ability to synthesize is considered an active, reflective competence, which is critical for design competency (Kolko, 2010a). It should therefore be an important goal of design-oriented education to make research, generative design, and design synthesis explicit, and aid students to reflect upon this in their practice (Stolterman, 2008). The transitions between research, generation, and synthesis are anchored in the design process, which is constant albeit with varying focus depending on theme for the project.

Academic journals and popular press both highlight the importance of creativity and innovation in business (e.g. Huber, Leigh, \& Tremblay, 2012). In particular, creative thinking is important for design-oriented organizations such as architecture, industrial design, web design, and advertising agencies. Unpacking the concept of creativity is difficult, and even though attempts have been made, a coherent theory of creativity is still lacking (Huber et al. 2012). It is, however, clear that a critical aspect of creative, yet rigorous, design lies in the design process (Buxton, 2010). The design process is a tool for creating meaning for the designer. It helps making the problem space visible (Antunes et al., 2014) and allow for creative "leaps" in the form of design synthesis (Kolko, 2010a). Throughout the decades, a vast range of design processes have been suggested, evaluated, and recommended. However, the consensus within the design communities of practice seems to be that it is neither possible nor desirable to settle on one particular design process (Buxton, 2010), since that would imply fostering a prescriptive, instrumental, and normative way of looking at design. The dynamic notion of a creative design process stands in contrast to such an approach. However, there are certain characteristics of a design process that are general enough to cover a large set of process requirements, yet specific enough to distinctly characterize it from other types of non-generative problem-solving processes. One of the prime examples of 
this is the notion of divergent vs convergent modes of designing, where explorative sketching forms the basis for expanding the design space, and refinement and prototyping focus the design on a specific target (Brown, 2008; Buxton, 2010). The second aspect is user-centered design, which puts the focus on human needs and heavy end-user involvement in the design process (e.g. Löwgren \& Stolterman, 2004). A third aspect prominent in a digital design process is the notion of iterative refinement. This is part of most design processes to date, including agile approaches (Martin, 2003), goal-directed design (Cooper et al., 2012), and design thinking (Brown, 2008). Figure 1 shows a generic schematic of a user-centered design process with research and analysis phases (Goodwin, 2011), divergent sketching, convergent prototyping phases (Buxton, 2010), and iterative refinement, eventually leading to an artifact that becomes part of an accumulated portfolio of design competence and artifacts.

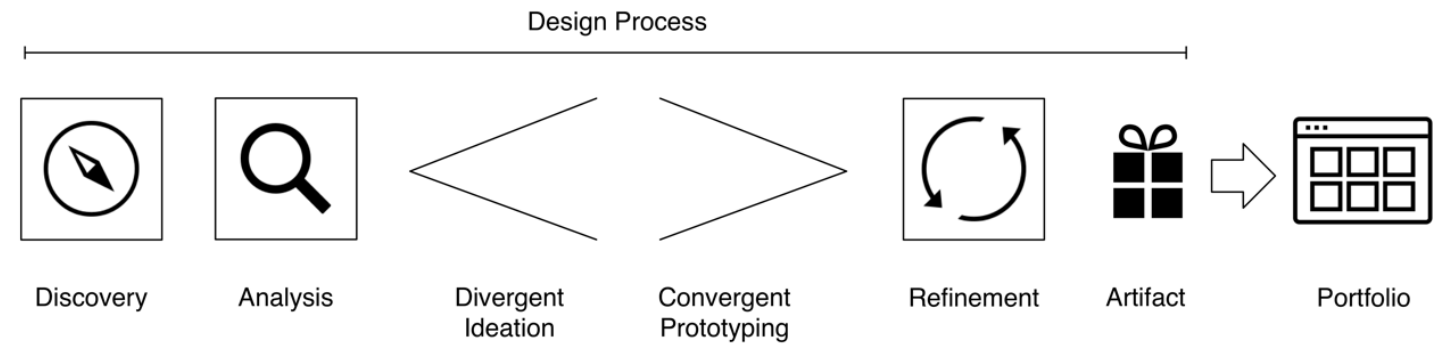

Figure 1. Generic steps in a user-centered, creative, and iterative design process

No process can guarantee innovative output, but being confident in a design process is necessary to maintain high quality creative design output day in and day out in a professional design career. To this point it has even been suggested that design-oriented organizations should put as much effort into evolving the organization's design process as in the actual projects at hand (e.g. Buxton, 2010).

The lack of creativity in design and technology courses has been noted by Barlex and Trebell (2008). Furthermore, there is an evident lack of progression in design skills in various designoriented educational contexts (Barlex \& Trebell, 2008). This points towards a gap in IT education that needs to be addressed. By intentional progression of design challenges that enforces and drills a design process and encourages reflection, we might be able to raise the creative capabilities in our learning environments.

\section{Studio-Based Learning}

Learning in the studio is often aligned with theories on transformative learning (Boyd \& Myers, 1988; Selander, 2008), experiential learning (Kolb, Boyatzis, \& Mainemelis, 2001), and symbolic interactionism (cf. Blumer, 1986). Knowledge is viewed as something that is produced by active learners. The model is that the student, through investigation, critique, and assimilation, generates knowledge rather than that the teacher has a bank of knowledge that should be transferred to the students.

It should come as no surprise that the studio pedagogy puts a natural focus on procedural knowledge. This is important for several reasons. First, the creation of an artifact is inherent to design since it gives an increased understanding of the problem space a professional designer is addressing (Buxton, 2010). The procedural aspects of design are required for reflection-in-action and reflection-on-action (Schön, 1983) which are critical qualities for design practice. Furthermore, the studio is a suitable arena for implementing experiential learning, due to the inherent focus on experimentation with, and creation of, artifacts. In such an environment, procedural skills are naturally developed and promoted. The need to practice research methods, learning 
from one's mistakes, and providing an apprenticeship-style learning environment within designoriented Informatics has been reported as being an important challenge to take on for HCI education (Galliers \& Huang, 2012; Sas, 2006).

The third cornerstone in studio-based learning is that of social interaction as a vehicle to learn through dialogue. In most studios, this is mostly implemented as structured design critique sessions, as well as through a physical environment where dialogue and working close with peers is encouraged (Snyder et al., 2009). By providing a common theme for all projects in a course, the opportunity for meaningful dialogue between teams in the studio is also strengthened (Wärnestål \& Lindqvist, 2013).

Studio-based learning originated from the medieval arts and crafts guilds, where apprentices learned in studios of a practicing master. In more recent times, the studio concept has been formalized within, for example, Architecture, but has begun to spread to other disciplines, from the natural sciences to Informatics and HCI (Mewburn, 2011). This section outlines some key characteristics of studio-based education as it applies to IT design. General studio characteristics include:

- There are few - if any - traditional lectures. Work is student-initiated, and the instructor works as a catalyst or coach.

- Students work in teams and engage in collaborative dialogue, as well as critique sessions.

- Activities in the studio are focused on collaboration and learning-together. This includes the instructor, who is also seen as a co-designer.

- The responsibility for learning is naturally put on the student as she is considered and encouraged to be an "active design practitioner" rather than a passive recipient of information.

- The characteristics of the physical environment are critical. The studio is always open, and artifacts and work material are always accessible throughout the course. The studio is furnished to promote dialogue, often with round tables instead of lecture hall rows. Design deliverables are put on walls and whiteboards to fuel discussion and critique.

Considering the nature of studio-based work, we can draw parallels with professional design work and the studio. In particular, the studio environment echoes professional design practice in regards to the nature of the problems and the open, experimental, and communal nature of the studio. This learning environment has been noted to lend itself to familiarizing students with the steps and practices of creativity (Snyder et al., 2009):

- Production

- Students are first oriented towards a problem.

- Preparation occurs through gathering data about the problem.

- Artifacts are created.

- Performance

- Iterative and incremental progress is visible.

- Data are broken down and analyzed, and ideas emerge.

- Ownership is established over ideas and analysis.

- Results are visible and shared.

- Interpretation

- Group and individual perspectives are considered.

- Concentrated focus is paused to consider multiple meanings.

$\circ$ Awareness of communal discoveries is shared. 
$\circ$ Tolerance and ambiguity are encouraged.

- Critique

- Dialogue occurs among students.

- Synthesis occurs in comparing and contrasting interpretations.

- Ideas are evaluated to determine goodness of fit.

- Change and adaptation are enabled.

The design process implemented in the studio should incorporate and support the production, performance, interpretation, and critique steps outlined above, as well as explicit research, generative practice, and design synthesis.

The studio environment aims at fostering a culture of freedom, creativity, and activity where students gain confidence in their design competence and let them experience flow in their work. A necessity for this is to provide the right progression steps so students get a challenge that matches their current skillset. This progression within and between studio courses is like all other artifacts: it must be carefully designed to be successful.

\section{Design-Based Learning Sequences}

Design-based learning is characterized by open-ended, hands-on, authentic, and multidisciplinary design tasks resembling professional communities of practice (Puente, van Eijck, \& Jochems, 2013; Sas, 2006). The design-based learning environment stresses the notion of students "making meaning" through design, and having teachers that facilitate such a process through formative and summative assessment of both individuals and teams. Communication and peer-topeer interaction are critical aspects of a design-based learning environment. Indeed, communication as "making meaning" is conceptually close to design, which is seen as a way to configure social interaction and communicative resources (Selander, 2008). In this light, a user-centered design process - where emphasis is put on transparency, communication, user control, and participation (Löwgren \& Stolterman, 2004) - is a promising candidate for not only a rigorous design process (Garrett, 2010), but also a highly suitable process for learning and making meaning (Selander, 2008).

Selander (2008) presents a theoretical map that formalizes stages of a creative learning process. In short, the model describes a learning process starting with the teacher "staging" the course, including setting a theme for the course, making an inventory of available resources, and considering the curriculum of both the course and the program. As depicted in Figure 2, there are two transformational cycles following the staging. The primary cycle is focused on transforming and forming of knowledge where available media and modes are utilized. By the end of the primary cycle, students have formed a representation that mediates the transfer to the secondary transformational cycle, where reflection and meta-reflection comes into focus. The teacher's role in the primary cycle is mainly formative and facilitating (along the lines of design studio practice), whereas the role changes to summative assessment of the work. By setting up the learning sequence in this manner, both teachers and students can use the model as an evaluation and reflection tool at the end of the course.

Selander's theoretical lens coupled with a user-centered, creative design process implemented in a design studio environment are the fundamental building blocks for the design studio learning framework presented in the next section. 


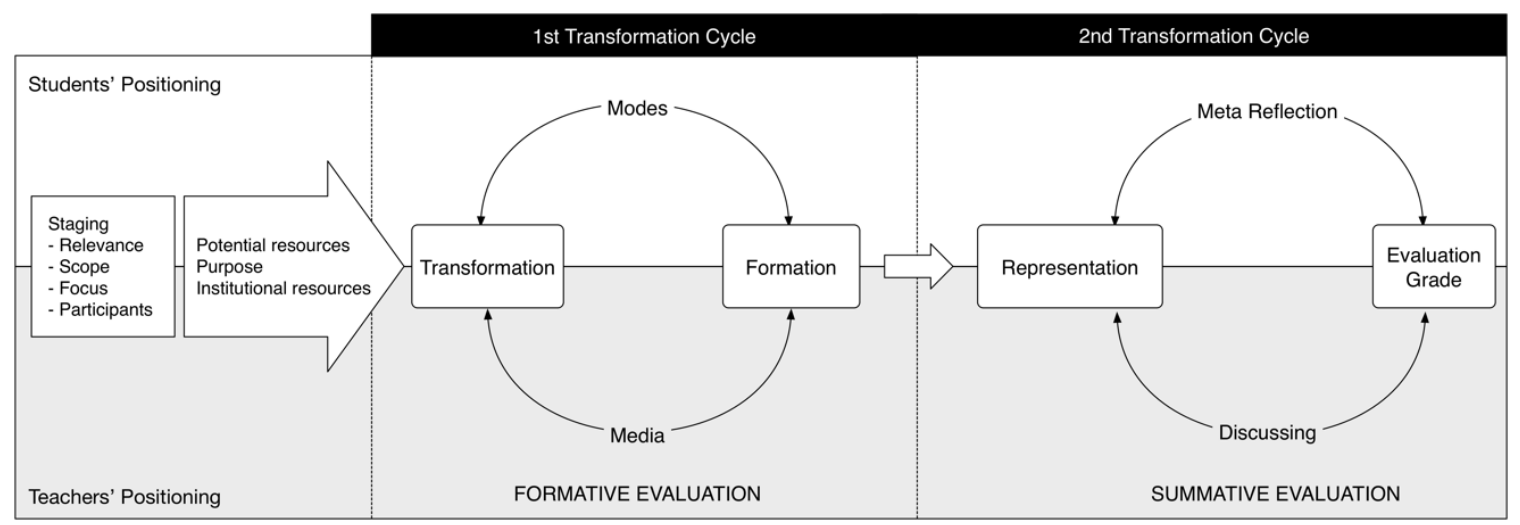

Figure 2. Transformation cycles in a formal learning sequence (after Selander, 2008)

\section{Formalizing Learning Sequences and Progression}

This section synthesizes transformational learning theory, the design studio environment, and the user-centered design process into a coherent framework for design-based learning and controlled progression in, and between, digital design studio courses in a Bachelor Informatics program.

\section{Transformation Cycles and the Design Process}

Figure 3 shows a representation of the relationship between the design process (see Figure 1) and transformational cycles (see Figure 2) in the learning environment of the design studio.



Figure 3. Digital design process in relation to transformational cycles in the design studio learning environment

\section{Staging and Positioning}

The importance of the teacher setting the scene at the beginning of the course is highlighted by Selander (2008). The purpose of the staging is to provide relevance, focus, scope, and motivation for the participants. The two main components for the pre-course staging are: (a) external assignments in the form of design briefs; and (b) a student goal and competence survey. 
For authentic design practice, the natural starting point for setting relevance, focus, and scope is the design brief; that is, a project assignment from an external client. A digital service design client is often a company, but can be any type of organization that faces a design challenge in the digital realm. By using external clients, a motivating quality of authenticity is also achieved. In the context of a learning environment, such as a studio course, we also include the students' goals and competencies as part of the scene-setting. This can be accomplished by sending out a survey that the students complete before the course starts. This is important for four reasons. First, it allows the student to explicitly assess his or her own learning goals and competence, thereby addressing student-centered scope and focus (Figure 3). Second, the instructor can set up balanced student teams by taking the survey responses into consideration. Third, by returning to the goals and competence survey at the end of the course, the teacher and student have a personalized tool for evaluating the development of the student's knowledge and skill progression. Fourth, allowing each student to explicitly submit her learning goals for the course, coupled with an external and authentic design brief, creates a motivating sense of relevance for the students.

\section{Transformational Cycle 1: Transformation and Formation}

The performative acts of seeking and transforming information, as well as producing new information by interviewing and contextual observation, are important meaning-making activities during the Discovery and Analysis phases (Figure 3). The models created in the analysis phase are typically standard HCI concepts such as personas, scenarios, and content models (Cooper et al., 2012; Löwgren \& Stolterman, 2004). These are actionable constructs used in the Divergent Ideation phase, where the students explore the design space through sketching (Buxton, 2010). By employing dialogue in the form of design critique (student-student, as well as teacher-student) and co-design with teachers and clients, students get feedback on their solutions while exploring the design problem at hand. This then evolves into the Convergent Prototyping phase, where the exploration starts to take a more concrete form as the team hones in on a specific solution (i.e. a formation).

The transition from transformation to formation has been found to be key in the process of meaning-making (Selander, 2008). As the design process in essence is a set of decisions and choices, the students are continually asked to reflect upon these choices. This serves two purposes: (a) being able to clearly articulate design decisions, which is a critical skill for a professional designer; and (b) supporting the meta-reflection and evaluation in the second transformation cycle.

\section{Transformational Cycle 2: Representation and Evaluation}

As students have selected modes and media that show what they find as central to their artifact, they enter an iterative process of refining their solution. As this takes part towards the closing of the course, more emphasis is put on presentation and evaluation of the project (including reflection of process and artifact).

The teachers' role switches from formative assessment to summative assessment as they turn to grading reflections and presentation of the various representations of the design problem and process. The teachers' interventions are still supportive of course, but the focus shifts from co-design to facilitating discussions towards meta-learning and consciousness-raising activities (Selander, 2008).

The student also returns to the goal and competence survey from the Staging phase and use that as a tool for reflection on what has been achieved during the course.

As every studio is part of a larger design-oriented education, the cumulative design Portfolio (Figure 3) built up throughout previous studio courses plays an important role in the students' continuous reflection-on-action (Schön, 1983). 
The artifact itself and a presentation of the same for the stakeholders, a reflection on the design process, a reflection on the goals and competence survey, and meta-reflection on accumulated learning outcomes, form the basis for summative assessment.

\section{Managing Progressions Between Studio Courses}

This section presents the progression model, which consists of a description of seven dimensions that can be used to characterize studio course progressions. The model is then exemplified with a four-step progression implementation currently being used in a three-year design-oriented undergraduate Informatics program.

\section{Design-Specific Dimensions for Progression}

Based on the theoretical concepts presented above regarding aspects of design, creativity, and learning, we have identified seven dimensions relevant to design-oriented studio-based learning that characterize aspects of digital design practice. Table 1 presents the dimensions and associated scales used to characterize the studio course challenges.

Table 1. Design space dimensions D1-D7 characterizing challenges in design studio courses

\begin{tabular}{|c|c|c|}
\hline & Dimension & Meaning \\
\hline D1 & Design Problem & $\begin{array}{l}\text { The design problem ranges from well understood and closed (routine) to ambiguous, open, } \\
\text { and loaded with internal conflicts in its sub-problems ("wicked"). }\end{array}$ \\
\hline $\mathrm{D} 2$ & $\begin{array}{l}\text { Theoretical } \\
\text { Base }\end{array}$ & $\begin{array}{l}\text { This dimension aims to capture how challenging the theoretical underpinnings are related } \\
\text { to the content of the studio course. If the course theme is captured within theory that is } \\
\text { established within e.g. HCI or Informatics it is considered less of a challenge, compared to } \\
\text { cross-disciplinary themes where current HCI theory is lacking. The latter case may require } \\
\text { students to contribute to the theory-building themselves. }\end{array}$ \\
\hline D3 & Perspective & $\begin{array}{l}\text { The design challenge may be tactical or strategic. A tactical design focuses on a specific } \\
\text { product or service, and tends to measure objective product attributes, whereas strategic } \\
\text { design takes into account long-term use, sustainability and viability, and measures effects } \\
\text { on user experience in relation to identity, brand, and business model, etc. }\end{array}$ \\
\hline D4 & Target Platform & $\begin{array}{l}\text { The target platform (or device) can be given as part of the design problem ("Your mission } \\
\text { is to build a website and e-shop for product X"), or it can be open-ended ("Your mission is } \\
\text { to build a service that increases physical well-being") and leave the choice of target plat- } \\
\text { form open. }\end{array}$ \\
\hline D5 & Design Tools & $\begin{array}{l}\text { This dimension is related to D4, since the choice of platform often dictates the availability } \\
\text { of design tools. On the less challenging end are mature and easily available tools for e.g. } \\
\text { website prototyping. Projects residing on the more challenging end of this dimension re- } \\
\text { quire teams to build their own design tools for new interaction modalities. }\end{array}$ \\
\hline D6 & $\begin{array}{l}\text { Service } \\
\text { Complexity }\end{array}$ & $\begin{array}{l}\text { Most systems do not exist as isolated islands, but are part of a larger digital (and analogue) } \\
\text { user experience context. A product or service is typically experienced through multiple } \\
\text { touch points, across several channels, distributed in time and place. To regress the chal- } \\
\text { lenge in this dimension the problem can be limited to a single device and a single touch } \\
\text { point in the service ecosystem. On the more challenging, and realistic, end of this dimen- } \\
\text { sion designers are expected to work on multiple devices and multiple touch points, as well } \\
\text { as designing the user journeys between them. }\end{array}$ \\
\hline D7 & $\begin{array}{l}\text { Contractor's } \\
\text { Digital Design } \\
\text { Literacy }\end{array}$ & $\begin{array}{l}\text { The contractor (or client) who initiates the original theme or design problem can be highly } \\
\text { proficient in digital service design, and have a robust understanding of what the service } \\
\text { will entail, what a user-centered design process looks like, and how to manage complexity } \\
\text { along dimensions D1-D6 above. On the other end of the scale, the contractor can be firmly } \\
\text { set in a completely different domain or field, and is neither skilled nor experienced in } \\
\text { terms of digital service design and user-centered design processes. In the former case, the } \\
\text { design team has a natural ally in the client, who can indeed function as a mentor through- } \\
\text { out the process. In the latter case, the responsibility of managing the process and argue for } \\
\text { design decisions becomes a heavier load on the designers. }\end{array}$ \\
\hline
\end{tabular}


The design process is the structure that these dimensions are anchored to. The design process is, as noted previously, one of the most valuable assets in a designer's toolbox. From a learning point of view, the process also ties together the studio courses, and help students confidently work even if the challenges progress along dimensions D1-D7. Though the content and theme of the courses change, the design process remains basically the same (see Figure 1). It provides a lens of understanding for problem definition, design generation, and synthesis. It is therefore important that the design process is the anchor for all studios, when other variables change in the progression between studio courses.

\section{Integration Between Studios and Traditional Courses}

In most academic undergraduate programs, it is probably not feasible - and perhaps not even desirable - to solely rely on studio courses. "Traditional" courses have their benefits, and it is important that they are designed well, as well as their interplay with the studio courses. Naturally, it is beneficial for the studio if the preceding course content prepares the students with knowledge and tools that they need to be able to focus on the design-oriented aspects of the studio content. And vice versa: the reflections done in the studio course should ideally prepare the students for the regular courses that follow.

For example, a studio course dealing with website design and development could be preceded by preparatory courses in web usability, dynamic web programming, and HTML and CSS prototyping, so that the valuable time in the studio can be focused on design-oriented aspects, and allow the students to work "for real" through the design process, rather than spending time on introductory exercises and code syntax tutorials.

\section{Method}

The context for this study is a series of studio learning experiences that were created by implementing the framework of formal learning sequences in a design-oriented three-year undergraduate Informatics program. The implementation is a synthesis of a user-centered design process and the transformational cycles depicted in Figure 3. In the program, four design studio courses are distributed evenly throughout the three years, with one studio at the end of the second semester, one during the third semester, one during the fourth semester, and the final studio course in the sixth semester, right before the bachelor thesis project is carried out. A semester is 20 weeks long. Each design studio course was five weeks long (full-time). During the studio course, the students form teams of 4-6 participants using the pre-course survey method described above (see section Staging and Positioning). The four studio courses were modeled as a continuous progression along the seven dimensions described in Table 1 (see Figure 4).

The learning experiences in the studio courses were then evaluated by collecting written reflections from teachers, students, and external clients. Specifically, reflections were collected from: (a) 40 students who have participated in at least two consecutive studio courses within the Informatics program outlined above; (b) four teachers who have been involved in one or more studio courses; and (c) five external contractors who have provided design briefs, and co-supervised projects in at least one studio course.

Figure 4 shows the program's four studio courses plotted on the dimensions D1-D7 found in Table 1 . The courses are given throughout three years of undergraduate studies, and are integrated with the program's more traditional courses. This section outlines the studio progression based on the model presented in the previous section. 
Dimension

Design Problem

(D1)

Theoretical Base

(D2)

Perspective (D3)

Target Platform

(D4)

Design Tools (D5)

Service

Complexity (D6)

Client's Design

Literacy (D7)
Studio Courses (1-4)

well-understood,

closed

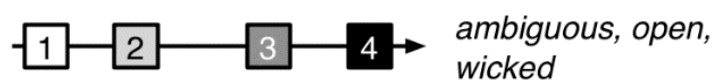

wicked

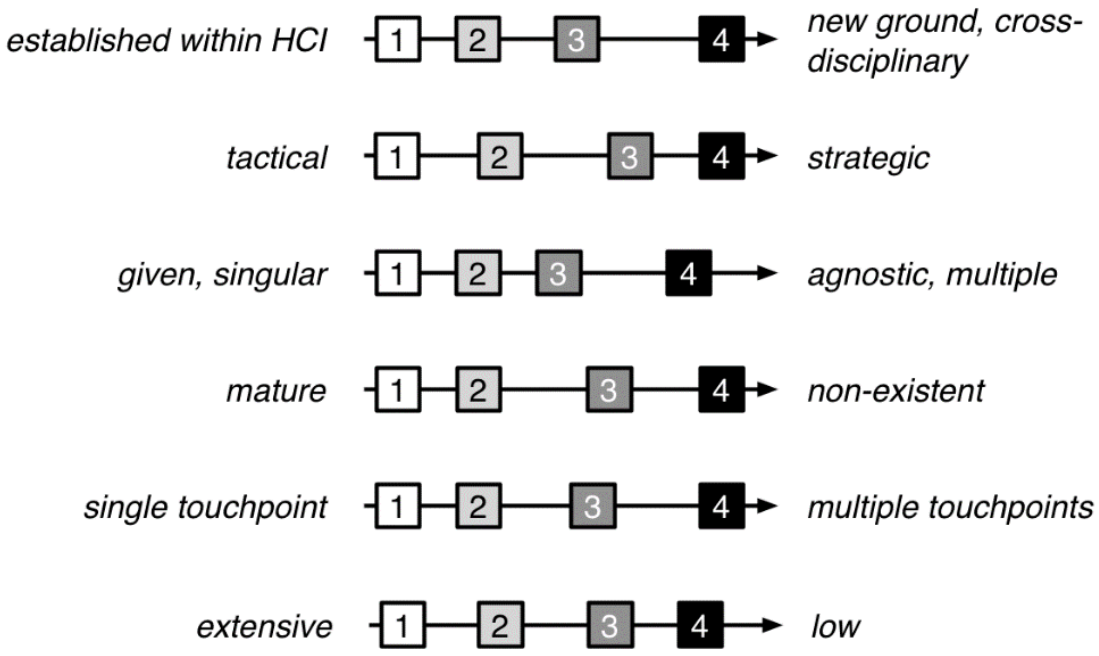

Figure 4. Example progression for four undergraduate design studio courses. Studio 1: Web design; Studio 2: Game and Narrative; Studio 3: Health Innovation; Studio 4: Sustainability and Critical Design.

\section{Studio 1: Web Design}

The first studio course is given in year one, after the fundamental courses the first semester has been given. The purpose of the course is to let the students experience the design process as well as the collaborative culture of a design studio environment and critique sessions. Therefore, all dimensions are tuned to the left-end side of the scales. The problem facing the teams is to design and build a standard website for a desktop or laptop screen. This means that the design problem (D1) is well defined. The aims are to: (a) establish and familiarize students with the design process; and (b) allow them to get hands-on practice with the tools that they have worked with in previous courses (currently HTML5, CSS, and jQuery). The underlying theory (D2) for the problem consists of standard HCI theory regarding usability and interaction design for the web. The perspective (D3) is tactical in nature, since students are expected to work with standard components and established frameworks for web development, and towards a given, single target platform (D4). The availability of mature design tools (D5) for website development is high (e.g. Balsamiq, Axure, framer.js, and Bootstrap to mention a few prototyping tools). The expected resulting artifact is a "stand-alone" website, constituting the only end-user touch-point in this modest sandbox example case. The service complexity (D6) is thus low. We engage with contractors who operate within the space of web and app development. This means that the contractors' design literacy (D7) is high, and the stakeholders at the contracting organization therefore can function as mentors for the design students.

\section{Studio 2: Game and Mobility}

In the second studio (year two) the students take a step "into the wild". Armed with preparatory courses in ethnographic methodology such as contextual observation and interviewing, and game mechanics and narrative, they are expected to approach a slightly more open-ended design prob- 
lem (D1) of designing a digital service for a mobile context and user group based on game mechanics. This also opens up the theoretical dimension (D2), since students need to work from theoretical perspectives such as game theory and behavioral psychology that reside outside the core of the HCI field. The perspective (D3) is still leaning towards the tactical end, with a focus on developing on a well-known smartphone or tablet target platform (D4). Design tool availability for gamified and mobile services are rapidly maturing, however at the time of writing they have yet to surpass traditional website design tools. Therefore, the challenge in the design tool dimension (D5) has increased. Service complexity (D6) is still at the "lower" end of the scale, but just as in the case of $\mathrm{D} 4$, there is room for developing the design towards transitions between e.g. mobile and a desktop-based version of the service. The contractors are primarily game design studios or digital advertising agencies that provide gamification design briefs. They are thus mostly experienced in the field, with a position towards the left side of the D7 dimension.

\section{Studio 3: Health Innovation}

The most significant change in the third studio (year two) progression concerns dimension D1. The design problem is more open than the previous two studio courses. The objective is to design a service that will help users improve their health in some way. Depending on where the research will take the students, the target platform (D4) can be anything from wearable or mobile health monitor technology, a social media website designed to improve social and mental health, to novel IT enhancements for medical professionals. For some of these applications students would probably have to either build their own design and prototyping tools, or work on paper, since design tool support (D5) cannot be guaranteed. Potentially, this could also require a lot along the theoretical dimension (D2), since literature and research from non-HCI fields would come into play. Possibly, there is an opportunity for students to contribute theory-wise due to the crossdisciplinary perspective of the health innovation theme. It comes with the theme to work with a more strategic perspective (D3), since human health is a long-term venture to design for.

Since D1-D5 are all slightly expanded compared to the previous two studios, it would be wise for the instructor to coach the student teams to make demarcations along the service complexity dimension (D6), and keep the complexity on a similar level as studio 2. Stakeholders and clients in this space are typically operating in healthcare or fitness/wellness industries, where the digital design literacy often can be low (D7).

\section{Studio 4: Sustainability and Critical Design}

The final studio course is given at the third year, and with three studio courses that have gradually been progressed behind them, students are ready to tackle challenges along all seven dimensions. The theme is open-ended and strategic: "Design a (set of) service(s) that addresses ecological, economic, and/or social sustainability from a user, organization, or societal perspective."

In our model, this pushes toward the complex end of all dimensions (D1-D7), since it requires students to approach a complex ecosystem of services, possibly on several platforms, with effects that need to be strategic and long-term. This will require theory from multiple fields, as well as a covering new ground, since sustainability issues are still far from resolved in the information systems field (Melville, 2010). Clients in this space are typically operating within fields other than digital design. A final layer of complexity is added by treating the design space under a critical design approach (Barab, Thomas, Dodge, Squire, \& Newell, 2004; Dunne, 2005), where the artifact lies outside mainstream status quo, and instead provokes perceptions of digital services, and emphasizes socio-cultural aspects of what the digital service's effects might have on individuals, organizations, and society. 


\section{Results and Analysis}

Forty written student reflections from three studio courses that implement this framework were collected, along with four teacher interviews, and five interviews with external contractors involved in the same studio courses. This section summarizes the results of these reflections and interviews. The student data comprises an average of 976 words per reflection (median 915 words per reflection). Teacher data consists of an average of 1,087 words per reflection (median 1,004 words per reflection). External contractors provided oral feedback, which was put into notes by the program director and course supervisor. All data was collected after all course activities were completed.

In order to model this rich data, a qualitative analysis on the material was made. The data were combed for topics related to learning experiences, and meaning-bearing phrases from the reflections and interviews were sorted into groups based on similarity. This allowed clusters to emerge for each category of respondents (students, teachers, and clients). The clusters were then given theme names that reflects the content. In total, eleven themes were identified.

\section{Students' Feedback}

There were four main themes that emerged in the student reflections: Industrial context and relevance, motivation, hands-on experience, and learning.

Industrial context and relevance: Students appreciate the authenticity of external projects that solve "real" problems. This is most evidently expressed as adding value to their portfolio. One student writes:

A real project from a company looks better in a résumé than a fictional lab exercise project. Plus I learn a lot more at the same time.

Motivation: Students report that they feel "seen" and "important" to a larger extent compared to traditional courses. This makes them more motivated. Relevance and motivation are summarized in the following student quote:

The [Game and Mobility] studio was the most demanding course so far. Also the most fun! With real briefs I feel that I as a student MATTER. There's no better motivation than that.

Hands-on experience: Students report that they appreciate the practical real-world problemsolving experience of studio courses. They typically report that they learn effectively and efficiently by solving design problems. Some students make comparisons between studio courses and "traditional" courses (i.e. courses based on lectures and written exams at the end of the course), and all favor the studio approach.

I think I learned a lot more by working on-site with the users, compared to what I usually learn in a traditional lecture.

Learning: Some students reflected upon the second transformation cycle, putting effort in identifying signs of their own learning. By relating back to the pre-course survey on competencies and goals, students were able to clearly articulate what - and how - they had learned in the studio courses. This is significant from a learning perspective, since being able to articulate learning and identify tangible signs of learning outcomes is an important skill. This meta-perspective is summarized by one of the students:

As it turns out, the most important skill I keep developing in the studio is learning how to learn. 


\section{Teacher's Feedback}

In the teacher data, five categories emerged: Signs of learning, Planning aid, Satisfaction, Teacher skill development, and Peer-to-peer learning.

Signs of learning: Teachers reported that the framework helped them to visualize and track the students' transformation process within a course. Aided by the cycles described by the framework, nuances of knowledge construction and understanding are made visible, and thereby being easier to evaluate and discuss with the students.

The cycle model [Figure 3] provided me with a map that allowed me to align the focus of the conversations in the studio with the design process as the course progressed.

Planning aid: The progression model (Figure 4) was reported as being helpful when planning the course, and provided a tangible representation that aided in the teacher and program director in their mutual planning discussions.

Satisfaction: Teachers reported that the time spent in the studio was generally perceived as more meaningful compared to standard lecturing. However, the meaningfulness requires some preparatory work, and communicating to the student teams that questions and issues should be prepared for sessions where teachers are available. Otherwise students may not be in a position to make the most use of the teacher's presence. The formal critique sessions help to get concrete conversations started, and the more informal sessions allow for interactions between students and teachers to be maintained.

Teacher skill development: One teacher reported that he felt energized by having to "learn new technologies" in order to contribute in a meaningful way to the specific student project at hand:

I have worked with Flash for a long time, but this [the student team's problem] had to do with JavaScript. So I went back to my office and read up on jQuery so I could get back and help the students.

While the quote above indicates a positive sentiment and opportunity for personal skill development, there is of course the risk of feelings of inadequacy if the teacher would feel that $\mathrm{s} / \mathrm{he}$ does not master the technology being dealt with. However, this aspect was voiced from a positive viewpoint by one of the teachers, who noted that the lecture preparation time needed in traditional courses could now be used to stay up-to-date with the current state of the field of HumanComputer Interaction and technologies instead.

Peer-to-peer learning: All teachers note the emergence of peer-to-peer learning among the students. Examples include student-run workshops and peer tutoring between students that happen naturally not only within, but also between, student groups. Teachers and students alike view the peer-to-peer learning activities as very positive and beneficial.

\section{External Clients' Feedback}

Two themes emerged in the client interviews: competence assessment and collaboration.

Competence assessment: Being able to work closely with a group of students was viewed as a valuable opportunity to assess the competence of the students. One of the clients expressed this as:

The course is like a five week hiring interview!

Collaboration: All clients were unanimously positive to collaborate with student teams. They appreciated getting "fresh eyes on the problem". Several of the external clients mentioned that they view the opportunity to be involved in program and course content development as both fun and valuable. One client also expressed positive remarks regarding the extended possibility to 
continue working more closely with the university in general; not only in terms of education, but within research as well. The desire to initiate and maintain collaboration between industry and academia is required from both parts in order to happen, and the interviews indicate that both parts see value in such collaboration.

\section{Discussion}

This paper has presented a framework of design-based learning consisting of a studio progression model and a synthesis of transformational learning cycles and a user-centered design process. The progression model is aimed towards design-oriented studio courses in the context of digital design. The aim of the framework is to support course developers and instructors to implement effective learning, and to provide a tool for systematically increasing the design challenge for the students in the studio so that the students eventually will be able to confidently take on openended, strategic, and complex design challenges for contemporary and future devices and target platforms. The model has been used to design a four-step studio course progression for a threeyear undergraduate education program. The initial evaluations reported on here indicate a high rate of student motivation and learning goal achievement, a high rate of teacher satisfaction and skill development, and a high rate of satisfaction among external contractors.

Furthermore, teachers and students both report that learning has occurred, based on various indicators such as in the students' use of new terminology, problem-solving by design, students' adoption of new dialogue genres (critique, presentations), and reflections on cumulative design portfolio construction. The various manifestations of such learning indicators - "signs" (Selander, 2008) - are included as an integral part of the proposed framework, making them explicit and important for students and teachers alike.

The proposed framework, in itself, can be viewed as both a design and evaluation tool for the studio teacher. First, it serves as a way to create a design-oriented curriculum and incremental progression for a series of design studio courses for a larger learning context such as an educational program. Work in the studio caters for reflection-in-action, and this has been part of the studio learning for a long time. The work formalizes this in terms of Selander's (2008) notion of (meta-) reflection in the second transformation cycle. But design practice is also dependent on reflectionon-action, where the continuous reflection on previous challenges elevates the students to be able to take on harder challenges as they develop. This progression should not be left to chance, but needs to be carefully designed. It is our hope that the framework presented herein is helpful in that regard.

Second, the framework gives instructors a tool for tweaking the challenge and complexity of the course at "run-time", in order to meet the needs and capabilities of the student group at hand. Should a student (or team of students) need a harder challenge to meet their potential, the instructor can select a dimension and progress it as a form of scaffolding. On the other hand, if the default challenge is too hard for students, or if they have chosen a particularly complex or challenging route on some of the dimensions, the instructor could coach the students to regress other dimensions so the workload can still be manageable and fruitful.

Third, the dimensions in the progression model can serve as a benchmark for evaluation of design work, and therefore be an examination support tool as part of the summative assessment step of the framework. Instructors can develop grade guides based on the seven dimensions as a designspecific framework for assessing the students' work. This needs further study and we are currently working on developing such guidelines for our studio courses in order to evaluate this approach.

Fourth, the seven dimensions can be used to visualize design aspects in the learning environment. By characterizing the studio's design challenges according to the seven dimensions and make 
these explicit towards the students at the start of the course, the model can help learners understand where their effort should lie, and clearly point toward goals for future studio courses in their education.

The studio framework presented herein facilitates critical thinking, self-directness, and experience-based knowledge construction. Students tend to focus naturally on collaborative learning, peer-to-peer learning, and get valuable experience in dealing with complex design problems and external clients. The students self-report a high degree of learning in the studio course, and the various components of the framework helps students articulate when and how learning has occurred. It is important to note, however, that this reflects the students' own experience of learning. A more objective (if possible) approach to measure learning outcomes from the studio-based learning experience is an interesting focus for future research.

Design-based work in the studio also exposes a transformation of the role of the teacher. The studio courses require teachers to become more coach-oriented, and to take on a role that supports the students to construct relevant knowledge in an active and rigorous fashion based on hands-on experience and collaborative dialogue. In some cases, this may require teachers to modify their way of teaching, especially if they are used to more traditional lecturing. Any such adjustments may initially require time resources and collaboration. Supporting teachers to excel in this new role requires advancements of teaching methods and techniques, which should be a valuable path for future pedagogical research.

\section{References}

Antunes, P., Xiao, L., \& Pino, J. A. (2014). Assessing the impact of educational differences in HCI design practice. International Journal of Technology and Design Education, 24(3), 317-335.

Barab, S. A., Thomas, M. K., Dodge, T., Squire, K., \& Newell, M. (2004). Critical design ethnography: Designing for change. Anthropology \& Education Quarterly, 35(2), 254-268.

Barlex, D. M., \& Trebell, D. (2008). Design-without-make: Challenging the conventional approach to teaching and learning in a design and technology classroom. International Journal of Technology and Design Education, 18(2), 119-138.

Blumenthal, M. S., Inouye, A. S., \& Mitchell, W. J. (2003). Beyond productivity: Information, technology, innovation, and creativity. Washington, DC: National Academies Press.

Blumer, H. (1986). Symbolic interactionism: Perspective and method. Berkeley, CA: University of California Press.

Boyd, R. D., \& Myers, J. G. (1988). Transformative education. International Journal of Lifelong Education, 7(4), 261-284.

Brown, T. (2008). Design thinking. Harvard Business Review, 86(6), 84.

Buxton, B. (2010). Sketching user experiences: Getting the design right and the right design. San Francisco, CA: Morgan Kaufmann.

Cho, J., \& Cho, M.-H. (2014). Student perceptions and performance in online and offline collaboration in an interior design studio. International Journal of Technology and Design Education, 24(4), 473-491. doi: 10.1007/s10798-014-9265-0

Cooper, A., Reimann, R., \& Cronin, D. (2012). About face 3: The essentials of interaction design. Indianapolis, IN: John Wiley \& Sons.

Cross, N. (2001). Designerly ways of knowing: Design discipline versus design science. Design Issues, $17(3), 49-55$.

Dahlbäck, N., Jönsson, A., \& Ahrenberg, L. (1993). Wizard of Oz studies - why and how. KnowledgeBased Systems, 6(4), 258-266. 
Dunne, A. (2005). Hertzian tales: Electronic products, aesthetic experience, and critical design. Cambridge: MIT Press.

Galliers, R. D., \& Huang, J. C. (2012). The teaching of qualitative research methods in information systems: an explorative study utilizing learning theory. European Journal of Information Systems, 21(2), 119-134.

Garrett, J. J. (2010). The elements of user experience: User-centered design for the web and beyond. Berkeley, CA: Pearson Education.

Goodwin, K. (2011). Designing for the digital age: How to create human-centered products and services. Indianapolis, IN: John Wiley \& Sons.

Huber, A. M., Leigh, K. E., \& Tremblay, K. R., Jr. (2012). Creativity processes of students in the design studio. College Student Journal, 46(4), 903-913.

Kolb, D. A., Boyatzis, R. E., \& Mainemelis, C. (2001). Experiential learning theory: Previous research and new directions. In R. J. Sternberg and L. F. Zhang (Eds.). Perspectives on thinking, learning, and cognitive styles (pp. 227-247). Mahwah, NJ: Lawrence Erlbaum.

Kolko, J. (2010a). Exposing the magic of design: A practitioner's guide to the methods and theory of synthesis. New York: Oxford University Press.

Kolko, J. (2010b). On experiences, people, and technology. Interactions, 17(6), 80.

Kolko, J. (2011). Craftsmanship. Interactions, 18(6), 78-81.

Levy, J. (2015). UX Strategy: How to devise innovative digital products that people want. Sebastopol, CA: O'Reilly Media.

Löwgren, J., \& Stolterman, E. (2004). Thoughtful interaction design: A design perspective on information technology. Cambridge, MA: MIT Press.

Martin, R. C. (2003). Agile software development: Principles, patterns, and practices. Englewood Cliffs, NJ: Prentice Hall.

Melville, N. P. (2010). Information systems innovation for environmental sustainability. MIS Quarterly, $34(1), 1-21$.

Mewburn, I. (2011). Lost in translation: Reconsidering reflective practice and design studio pedagogy. Arts and Humanities in Higher Education, 11(4), 363-379. doi: 10.1177/1474022210393912

Norman, D. A. (2007). Emotional design: Why we love (or hate) everyday things. New York: Basic Books.

Puente, S. M. G., van Eijck, M., \& Jochems, W. (2013). A sampled literature review of design-based learning approaches: a search for key characteristics. International Journal of Technology and Design Education, 23(3), 717-732.

Rittel, H. W., \& Webber, M. M. (1973). Dilemmas in a general theory of planning. Policy Sciences, 4(2), 155-169.

Sas, C. (2006). Teaching interaction design through practitioners' praxis. Proceedings of the 7th Annual conference of the higher education academy.

Schön, D. A. (1983). The reflective practitioner: How professionals think in action. New York: Basic Books.

Selander, S. (2008). Designs of learning and the formation and transformation of knowledge in an era of globalization. Studies in Philosophy and Education, 27(4), 267-281. doi: 10.1007/s11217-007-9068-9

Snyder, J., Heckman, R., \& Scialdone, M. J. (2009). Information studios: Integrating arts-based learning into the education of information professionals. Journal of the American Society for Information Science and Technology, 60(9), 1923-1932.

Stolterman, E. (2008). The nature of design practice and implications for interaction design research. International Journal of Design, 2(1), 55-65. 
Wang, T. (2010). A new paradigm for design studio education. International Journal of Art \& Design Education, 29(2), 173-183.

Wärnestål, P., \& Lindqvist, M. (2012). Course structuring for procedural knowledge in interaction design education. Proceedings of the 35th information systems research seminar in Scandinavia.

Wärnestål, P., \& Lindqvist, M. (2013). Designerly ways of teaching and learning: A course structure for interaction design. Learning in Higher Education, 9(1), 179-188.

Yoo, Y. (2010). Computing in everyday life: A call for research on experiential computing. MIS Quarterly, $34(2), 213-231$.

\section{Biography}

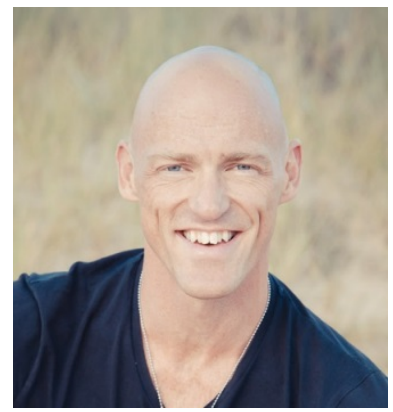

Pontus Wärnestål (PhD) is an award-winning Human-Computer Interaction researcher and merited senior lecturer with more than 15 years of User Experience Design work experience. He is Program Director for the Bachelor Informatics program Digital Design and Innovation given at Halmstad University in Sweden. Dr. Wärnestål received the Accomplished Teacher Pedagogical Merit degree for his work on active learning and studio-based pedagogy in 2014. 